\title{
Filtrados de Culturas Bacterianas Endofíticas na Motilidade, Mortalidade e Eclosão de Juvenis de Segundo Estádio de Meloidogyne javanica*
}

\author{
Rosemeire L. Naves ${ }^{1}$, Vicente P. Campos ${ }^{2} \&$ Ricardo M. Souza ${ }^{2}$ \\ ${ }^{1}$ Embrapa Uva e Vinho, Estação Experimental de Viticultura Tropical, Cx. Postal 241, CEP 15700-000, Jales, SP, \\ fax: (17) 3632-9666, e-mail: rose @ cnpuv.embrapa.br; ${ }^{2}$ Depto. Fitopatologia, Universidade Federal de Lavras, \\ Cx. Postal 37, CEP 37200-000, Lavras, MG
}

(Aceito para publicação em 01/06/2004)

Autor para correspondência: Rosemeire de Lellis Naves

NAVES, R.L., CAMPOS, V.P. \& SOUZA, R.M. Filtrados de culturas bacterianas endofíticas na motilidade, mortalidade e eclosão de juvenis de segundo estádio de Meloidogyne javanica. Fitopatologia Brasileira 29:384-388. 2004.

\section{RESUMO}

Filtrados das culturas de 40 isolados de bactérias endofíticas, obtidos a partir do sistema radicular de diferentes espécies de plantas foram testados na motilidade, mortalidade e eclosão de juvenis de segundo estádio $\left(\mathrm{J}_{2}\right)$ de Meloidogyne javanica. As bactérias foram cultivadas em meio líquido "trypic soy broth" por sete dias sob agitação constante a $28^{\circ} \mathrm{C}$, centrifugadas a $10.000 \mathrm{~g}$ por 15 min e o sobrenadante passado em filtro millipore de $0,22 \mu \mathrm{m}$ de abertura. Cerca de 100 ovos ou $100 \mathrm{~J}_{2}$ foram colocados em contato com cada filtrado bacteriano, para os ensaios de eclosão, motilidade e mortalidade. As avaliações foram feitas após 24 e 48 h para motilidade e mortalidade e após 15 dias para eclosão. Dos isolados testados, sete imobilizaram juvenis em
24 h, não ocorrendo recuperação da mobilidade após serem transferidos para água, provocando, dessa forma, porcentagens de mortalidade semelhantes à induzida pelo nematicida aldicarbe utilizado como controle. Os mesmos isolados também inibiram eficientemente a eclosão dos juvenis. Dois isolados provocaram a morte de mais de 90\% dos juvenis após 48 h de exposição. Diferentes diluições dos filtrados dos oito isolados mais eficientes também foram testadas. Maiores índices de mortalidade e redução na eclosão foram provocados pelo filtrado não diluído e pelas diluições em água 1:1 e 1:2 (v/v).

Palavras-chave adicionais: metabólitos bacterianos, controle biológico, fitonematóides.

\section{ABSTRACT}

Filtrates of endophytic bacterium cultures on motility, mortality and hatching of second stage juveniles of Meloidogyne javanica To obtaining the filtrates, bacteria were cultivated in liquid trypic soy broth medium for seven days at $28^{\circ} \mathrm{C}$ under constant stirring, centrifugated at $10,000 \mathrm{~g}$ for $15 \mathrm{~min}$ and the supernatant was filtrated by $0,22 \mu \mathrm{m}$ Millipore. Nonmotile Meloidogyne javanica and dead ones were counted 24 and $48 \mathrm{~h}$ later and hatched $\mathrm{J}_{2}$ were counted 15 days after setting up the experiment. Seven of 40 bacterial isolates tested immobilized the juveniles within $24 \mathrm{~h}$, and they could not recover even in water. This effect was similar to the aldicarb treatment used as control. The filtrates of isolates also inhibited egg hatching. Two isolates killed more than $90 \%$ of $\mathrm{J}_{2}$ after $48 \mathrm{~h}$ of exposure. Filtrate dilutions of the most efficient isolate in 1:1 and 1:2 (bacterial filtrate: water) also showed to have effective action on nematode behaviors.

\section{INTRODUÇÃO}

A utilização de bactérias no controle biológico de fitonematóides tem recebido maiores atenções nas últimas décadas, sendo enfatizadas aquelas do gênero Pasteuria (Thorne) Sayre \& Starr e as rizobactérias (Campos et al., 1998). O modo de ação desses organismos sobre os nematóides tem sido discutido em alguns trabalhos (Jonhston, 1959; Sayre, 1980; Sikora \& Hoffmann-Hergaten, 1996; Quadt-Hallmann et al., 1996). Algumas bactérias,como as dos gêneros Clostridium Prazmouwski, Desulfovibrio Kluyver \& Van Niel, Bacillus Cohn, Chromobacterium Bergonzini, Enterobacter Hormaeche \& Edwards e Pseudomonas Migula, já são comprovadamente capazes de produzir substâncias tóxicas aos nematóides (Jonhston, 1959; Lizuka et al., 1962; Rodríguez-

\footnotetext{
*Parte da Tese de Doutorado do primeiro autor. Universidade Federal de Lavras (2000)
}

Kábana et al., 1965; Wilt \& Smith, 1970; Ignoffo \& Dropkin, 1977; Jacq \& Fortuner, 1979). O efeito nematicida e nematostático de filtrados de culturas bacterianas foi inicialmente demonstrado por Lizuka et al. (1962) trabalhando com 134 isolados de bactérias do gênero Pseudomonas, dos quais 69 apresentaram intensa atividade nematicida contra Meloidogyne sp. Os mesmos autores demonstraram que filtrados de cultura de nove isolados de Enterobacter apresentaram alta atividade nematicida. Filtrados de cultura de Bacillus cereus Frankland \& Frankland, crescida em meio 'trypic soy broth' (TSB), mostraram atividade nematicida a juvenis do segundo estádio $\left(\mathrm{J}_{2}\right)$ e ovos de Meloidogyne javanica (Treub) Chitwood (Oka et al., 1993). Carneiro et al. (1998) testaram 21 isolados de Bacillus spp. em $\mathrm{J}_{2}$ de $M$. javanica em ensaios in vitro. A cultura total e o sobrenadante de Bacilllus thurigiensis brasiliensis Berliner e B. lateosporus Laubarch mataram juvenis recém eclodidos, após 24 e 48 h, enquanto B. thurigiensis aizawai 
Filtrados de culturas bacterianas endofíticas na motilidade, mortalidade...

Heimpel, B. thurigiensis morrisoni Bonnefoi \& Barjac e $B$. circulans Jordan causaram apenas imobilização ou redução de movimento. Apesar de pouca ênfase nas pesquisas, até o momento, as bactérias endofíticas têm merecido atenção, uma vez que esses organismos, devido à capacidade de viver no interior dos tecidos da planta, escapam da competição com outros microrganismos do solo (Misaghi \& Donndelinger, 1990). Assim, podem se adaptar e sobreviver melhor nesse ambiente competitivo, beneficiando-se do catabolismo de metabólitos das plantas (McInroy \& Kloepper, 1995). Poucas pesquisas têm sido desenvolvidas no Brasil sobre o antagonismo de bactérias endofíticas e nematóides.

No presente trabalho, objetivou-se avaliar, in vitro, o efeito dos metabólitos produzidos por bactérias endofíticas, isoladas a partir do sistema radicular de diferentes espécies de plantas, na motilidade, mortalidade e eclosão de $\mathrm{J}_{2}$ de $M$. javanica.

\section{MATERIAL E MÉTODOS}

\section{Isolamento de bactérias endofíticas}

Foram amostradas no campo raízes de braquiária (Brachiaria sp. L.), crotalária (Crotalaria sp. L.), milho (Zea mays L.), pimentão (Capsicum annum L.), cravo de defunto (Tagetes erecta L.), tomateiro (Lycopersicon esculentum Mill) e trigo (Triticum aestivum L.). Bactérias endofíticas foram isoladas de raízes dessas plantas utilizando-se o método da trituração de tecidos desinfestados superficialmente, segundo Mariano et al. (1997) e Assis et al. (1998), com modificações. Para tanto, raízes sadias foram cuidadosamente lavadas em água de torneira e transferidas para frascos contendo solução tampão fosfato-potássio (PB) 0,02 M esterilizada, ajustandose o pH para 7,0. Em seguida, foram submetidas à agitação vigorosa em equipamento do tipo orbital por $1 \mathrm{~h}$, sendo essa operação repetida quatro vezes, após troca da solução PB. Procedeu-se a desinfestação superficial das raízes por passagem em álcool $50 \%$ por $30 \mathrm{~s}$, hipoclorito de sódio $1 \%$ por $3 \mathrm{~min}$, seguindo-se três lavagens por $1 \mathrm{~min}$ em solução PB. Com o objetivo de desalojar bactérias epifíticas remanescentes nos tecidos superficiais, as raízes foram transferidas para frascos contendo solução PB esterilizada e submetidas a banho de ultra-som por 10 min. Nova desinfestação superficial das raízes foi feita com hipoclorito de sódio $1 \%$, por $3 \mathrm{~min}$, seguida de três lavagens em solução PB esterilizada. A seguir, as raízes foram novamente transferidas para frascos contendo solução PB esterilizada e submetidas a um novo banho de ultra-som por $10 \mathrm{~min}$. A trituração das raízes foi feita em almofariz e pistilo esterilizados, contendo PB, e o triturado submetido a um banho de ultra-som por 10 min para desagregação das partículas e células bacterianas. Procedeuse a homogeneização do triturado e posterior diluição em série em solução PB com fator de diluição 1:10. Retiraram-se, então, alíquotas de $100 \mu \mathrm{l}$ das diluições $10^{-1}, 10^{-2}, 10^{-3}$, que foram transferidas para placas de Petri contendo meio "trypic soy agar" (TSA) e espalhadas com alça de Drigalsky. Foram preparadas cinco placas para cada diluição, que foram mantidas a $28^{\circ} \mathrm{C}$, durante $48 \mathrm{~h}$, em câmara de crescimento. Para se verificar a eficiência da desinfestação superficial das raízes, após cada banho de ultra-som, como controle, alíquotas de $100 \mu$ l da solução de PB, utilizada para aquela operação, foram transferidas para placas de Petri contendo meio TSA e mantidas nas mesmas condições descritas para as placas preparadas com as diluições dos triturados. Não havendo crescimento bacteriano nessas placas dentro de $48 \mathrm{~h}$, os isolados obtidos pela trituração das raízes foram considerados endofíticos. As colônias bacterianas apresentando características morfológicas diferentes dentro de uma mesma amostra, foram repicadas em meio TSA pelo método de estrias em $\mathrm{T}$, visando à obtenção de colônias isoladas. Os isolados obtidos foram preservados em meio líquido peptona-glicerol em "freezer" a $-80^{\circ} \mathrm{C}$.

\section{Obtenção dos filtrados de culturas de bactérias endofíticas} Os isolados de bactérias foram transferidos para placas de Petri contendo meio TSA e incubadas a $28^{\circ} \mathrm{C}$ em câmara de crescimento. Após 48 h, pequena porção da colônia bacteriana foi repicada para frascos de vidro contendo $100 \mathrm{ml}$ de meio líquido "trypic soy broth" (TSB), que permaneceram a $28{ }^{\circ} \mathrm{C}$, por sete dias, em agitador orbital, sob agitação de $100 \mathrm{rpm}$. Após esse período, as culturas foram centrifugadas a $10.000 \mathrm{~g}$, por $15 \mathrm{~min}$, para remoção das células bacterianas e o sobrenadante passado em filtro Millipore com 0,22 $\mu \mathrm{m}$ de diâmetro de poro. Os filtrados obtidos foram utilizados nos ensaios de motilidade, mortalidade e eclosão $\mathrm{J}_{2}$ de $M$. javanica.

\section{Inóculo de $M$. javanica}

A partir de uma população pura de $M$. javanica caracterizada conforme descrito por Taylor \& Sasser (1978) e mantida em tomateiros suscetíveis (cv. Santa Clara) em condições de casa de vegetação, obteve-se uma suspensão de ovos utilizando-se a técnica de Hussey \& Barker (1973). Os ovos obtidos foram submetidos à desinfestação superficial em câmara de fluxo laminar por meio de imersão em sulfato de estreptomicina $0,1 \%$ por 5 min (Carneiro et al., 1998) e lavados por três vezes em água destilada e esterilizada, passando-se a suspensão através de peneiras com malha de $0,025 \mathrm{~mm}$. A suspensão de ovos obtida foi mantida em câmara fria, a $8^{\circ} \mathrm{C}$, até o momento do estabelecimento dos ensaios.

Para obtenção dos $\mathrm{J}_{2}$ utilizados nos ensaios de motilidade e mortalidade, preparou-se câmara de eclosão com tela e papel de espessura fina colocados em um béquer. Os $\mathrm{J}_{2}$ obtidos foram submetidos à desinfestação superficial com sulfato de estreptomicina $0,1 \%$, conforme descrito acima.

Três alíquotas de $1 \mathrm{ml}$ foram retiradas das suspensões obtidas e colocadas em caixa plástica para quantificação de ovos ou $\mathrm{J}_{2}$ ao microscópio estereoscópio.

\section{Eclosão de juvenis de $M$. javanica}

Em placas de Petri de $4 \mathrm{~cm}$ de diâmetro esterilizadas, foram colocados $5 \mathrm{ml}$ de cada filtrado para onde foram transferidos cerca de 100 ovos. As placas foram mantidas em condições de laboratório a $25 \pm 2{ }^{\circ} \mathrm{C}$. Após 15 dias avaliou-se a porcentagem de $\mathrm{J}_{2}$ eclodidos. Foram feitas cinco repetições 


\section{R.L. Naves et al.}

para cada tratamento, sendo utilizados como testemunhas água destilada esterilizada, meio TSB sem crescimento bacteriano e aldicarbe a $50 \mathrm{ppm}$. Foram instalados dois ensaios, utilizando-se 20 isolados em cada um, em delineamento experimental inteiramente casualizado. Os dados obtidos foram transformados em $\mathrm{y}=\operatorname{arcsen} \sqrt{x / 100}$ e submetidos a análise de variância. As médias de cada tratamento foram agrupadas pelo teste de Scott \& Knott (1974) a 5\% de significância.

\section{Motilidade e mortalidade $\mathrm{J}_{2}$ de $M$. javanica}

Em lâminas escavadas esterilizadas, foi colocado 0,6 $\mathrm{ml}$ de cada filtrado bacteriano, para onde foram transferidos cerca de $100 \mathrm{~J}_{2}$ recém eclodidos. As lâminas foram transferidas para placas de Petri contendo papel de filtro umedecido e mantidas em condições de laboratório a $25 \pm 2{ }^{\circ} \mathrm{C}$. Cada tratamento foi repetido oito vezes e as testemunhas foram água destilada e esterilizada, meio TSB sem crescimento bacteriano e aldicarbe a 50 ppm. Após 24 e 48 h, avaliaram-se as porcentagens de $\mathrm{J}_{2}$ aparentemente inativos, utilizando-se quatro repetições a cada período de avaliação. Foram considerados inativos os nematóides que apresentavam o corpo com aspecto retilíneo sob efeito de filtrados bacterianos ou retorcido, quando submetidos ao aldicarbe. Espécimens que permaneceram inativados $24 \mathrm{~h}$ após terem sido retirados do filtrado e transferidos para água foram considerados mortos. Foram instalados dois ensaios, sendo utilizados 20 isolados em cada um, em delineamento experimental inteiramente casualizado. Os dados obtidos foram transformados em $\mathrm{y}=\operatorname{arcsen} \sqrt{x / 100}$ e submetidos a análise de variância. As médias de cada tratamento foram agrupadas pelo teste de Scott \& Knott (1974) a 5\% de significância.

\section{Efeito de diluições dos filtrados bacterianos na motilidade, mortalidade e eclosão $\mathrm{J}_{2}$ de $M$. javanica}

Foram conduzidos ensaios com os oito isolados que se mostraram mais eficientes (MIL 1, MIL 4, MIL 5, MIL 7, MIL 16, MIL 21, BRA 5, BRA 15) na redução da motilidade e eclosão e aumento da mortalidade de $\mathrm{J}_{2}$ de $M$. javanica. Para tanto, os filtrados das culturas bacterianas foram diluídos em água destilada esterilizada nas proporções de 1:0, 1:1, 1:2 e 1:3 (v/v) (filtrado:água). Os ensaios foram instalados em delineamento experimental inteiramente casualizado e em esquema fatorial $8 \times 4$, sendo oito isolados e quatro diluições. Cada tratamento foi repetido quatro vezes. Os dados obtidos foram transformados em $\mathrm{y}=\operatorname{arcsen} \sqrt{x / 100}$ e submetidos à análise de variância. As médias de cada tratamento foram agrupadas pelo teste de Tukey a 5\% de significância.

\section{RESULTADOS E DISCUSSÃO}

Nos dois ensaios, alguns filtrados não causaram imobilidade ou mortalidade de $\mathrm{J}_{2}$, não diferindo, portanto, das testemunhas água e TSB, enquanto outros causaram imobilidade e mortalidade que não diferiram das causadas pelo aldicarbe. Entre esses dois extremos, alguns filtrados causaram diferentes graus de imobilidade e mortalidade aos $\mathrm{J}_{2}$ (Tabelas
1 e 2), indicando que, provavelmente, diferentes substâncias tóxicas a $M$. javanica, em quantidades diversas, são produzidas pela maioria dos isolados endofíticos testados, podendo, assim, afetar a patogênese dos nematóides nos hospedeiros.

A imobilidade ou mortalidade de $\mathrm{J}_{2}$ aumentou em todos os diferentes filtrados testados de 24 para $48 \mathrm{~h}$, em certos casos em até 15 vezes como verificado no filtrado do isolado TRI 1 (Tabela 1), indicando, provavelmente, que o somatório dos efeitos de substâncias diferentes demanda tempo para sua expressão e, portanto, o período de avaliação de $48 \mathrm{~h}$ seria mais apropriado. Contudo, filtrados de alguns isolados, como o MIL 1, MIL 4, MIL 5, MIL 16, MIL 21, BRA 5 e BRA 15 (Tabelas 1 e 2), causaram altas porcentagens de imobilidade e mortalidade de $\mathrm{J}_{2}$ já em 24 h, demonstrando, talvez, produzir grandes quantidades de substâncias tóxicas ou uma única ou mais substâncias com alta toxicidade capazes de imobilizar ou matar os $\mathrm{J}_{2}$ rapidamente. O filtrado do isolado MIL 7 proporcionou aumento nas porcentagens de imobilidade e mortalidade de $\mathrm{J}_{2}$ de 24 para $48 \mathrm{~h}$, igualando-se àquelas porcentagens de imobilidade e mortalidade provocadas pelo aldicarbe quando em 48 h de exposição (Tabela 2).

TABELA 1 - Porcentagens médias de juvenis do segundo estádio $\left(\mathrm{J}_{2}\right)$ de Meloidogyne javanica imóveis, mortos e eclodidos quando expostos aos filtrados das culturas dos isolados bacterianos endofíticos (primeiro ensaio in vitro)

\begin{tabular}{|c|c|c|c|c|c|}
\hline \multirow{2}{*}{ Isolado* } & \multicolumn{2}{|c|}{$\%$ de $\mathrm{J}_{2}$ móveis } & \multicolumn{2}{|c|}{$\%$ de $\mathrm{J}_{2}$ mortos } & \multirow{2}{*}{$\begin{array}{c}\% \text { de } \mathrm{J}_{2} \\
\text { eclodidos }\end{array}$} \\
\hline & $24 \mathbf{h}^{* *}$ & $48 \mathrm{~h}$ & $24 \mathbf{h}^{* *}$ & $48 \mathrm{~h}$ & \\
\hline TOM 1 & $2,50 \mathrm{f}$ & $4,75 \mathrm{e}$ & $2,00 \mathrm{~h}$ & $4,75 \mathrm{e}$ & $89,60 \mathrm{~b}$ \\
\hline CRO 1 & $0,25 \mathrm{~g}$ & $4,50 \mathrm{e}$ & $0,25 \mathrm{i}$ & $4,50 \mathrm{e}$ & $95,20 \mathrm{c}$ \\
\hline TRI 1 & $4,25 \mathrm{~d}$ & $66,50 \mathrm{~b}$ & $3,75 \mathrm{~h}$ & $66,50 \mathrm{~b}$ & $95,00 \mathrm{c}$ \\
\hline TRI 2 & $0,00 \mathrm{~g}$ & $1,50 \mathrm{e}$ & $0,00 \mathrm{i}$ & $1,50 \mathrm{e}$ & $89,40 \mathrm{~b}$ \\
\hline MIL 1 & $90,50 \mathrm{~b}$ & $98,50 \mathrm{a}$ & $90,50 \mathrm{~b}$ & $98,50 \mathrm{a}$ & $10,40 \mathrm{a}$ \\
\hline MIL 2 & $4,50 \mathrm{f}$ & $11,25 \mathrm{~d}$ & $3,75 \mathrm{~h}$ & $11,25 \mathrm{~d}$ & $93,20 \mathrm{c}$ \\
\hline MIL 3 & $3,25 \mathrm{f}$ & $4,75 \mathrm{e}$ & $3,00 \mathrm{~h}$ & $4,75 \mathrm{e}$ & $94,20 \mathrm{c}$ \\
\hline MIL 4 & $93,25 b$ & 96,25 a & $93,25 \mathrm{~b}$ & $96,25 \mathrm{a}$ & $14,20 \mathrm{a}$ \\
\hline MIL 5 & $91,50 \mathrm{~b}$ & $95,75 \mathrm{a}$ & $91,50 \mathrm{~b}$ & $95,75 \mathrm{a}$ & $9,20 \mathrm{a}$ \\
\hline MIL 6 & $1,00 \mathrm{~g}$ & $5,75 \mathrm{e}$ & $1,00 \mathrm{i}$ & $5,75 \mathrm{e}$ & $91,00 \mathrm{~b}$ \\
\hline MIL 9 & $33,75 \mathrm{f}$ & $4,25 \mathrm{e}$ & $2,75 \mathrm{~h}$ & $4,25 \mathrm{e}$ & $91,00 \mathrm{~b}$ \\
\hline MIL 10 & $54,25 \mathrm{c}$ & $78,50 \mathrm{~b}$ & $54,25 \mathrm{~d}$ & $74,10 \mathrm{~b}$ & $93,00 \mathrm{c}$ \\
\hline MIL 11 & $36,50 \mathrm{~d}$ & $76,25 \mathrm{~b}$ & $36,50 \mathrm{e}$ & $76,25 \mathrm{~b}$ & $92,80 \mathrm{c}$ \\
\hline MIL 12 & $7,00 \mathrm{e}$ & $10,00 \mathrm{~d}$ & $7,00 \mathrm{~g}$ & $9,25 \mathrm{~d}$ & $90,80 \mathrm{~b}$ \\
\hline MIL 14 & $2,25 \mathrm{f}$ & $5,00 \mathrm{e}$ & $2,25 \mathrm{~h}$ & $5,00 \mathrm{e}$ & $93,20 \mathrm{~b}$ \\
\hline MIL 16 & $90,00 \mathrm{~b}$ & $96,25 \mathrm{a}$ & $75,00 \mathrm{c}$ & 96,25 a & $12,20 \mathrm{a}$ \\
\hline MIL 17 & $5,25 \mathrm{f}$ & $10,25 \mathrm{~d}$ & $5,25 \mathrm{~g}$ & $10,25 \mathrm{~d}$ & $82,20 \mathrm{~b}$ \\
\hline MIL 19 & $52,00 \mathrm{e}$ & $72,00 \mathrm{~b}$ & $52,00 \mathrm{e}$ & $70,00 \mathrm{~b}$ & $88,80 \mathrm{~b}$ \\
\hline MIL 20 & $12,00 \mathrm{c}$ & $39,00 \mathrm{c}$ & $12,00 \mathrm{f}$ & $39,00 \mathrm{c}$ & $91,40 \mathrm{~b}$ \\
\hline MIL 21 & $85,25 \mathrm{~b}$ & $95,00 \mathrm{a}$ & $85,25 \mathrm{c}$ & $95,00 \mathrm{a}$ & $8,80 \mathrm{a}$ \\
\hline ÁGUA & $0,00 \mathrm{~g}$ & $0,00 \mathrm{e}$ & $0,00 \mathrm{i}$ & $0,00 \mathrm{e}$ & $96,60 \mathrm{c}$ \\
\hline TSB & $0,50 \mathrm{~g}$ & $2,75 \mathrm{e}$ & $0,00 \mathrm{i}$ & $2,75 \mathrm{e}$ & $96,20 \mathrm{c}$ \\
\hline ALDICARBE & $99,50 \mathrm{a}$ & $100,00 \mathrm{a}$ & $99,50 \mathrm{a}$ & $100,00 \mathrm{a}$ & $4,60 \mathrm{a}$ \\
\hline
\end{tabular}

\section{$(50 \mathrm{ppm})$}

Médias seguidas por letras distintas nas colunas, diferem entre si pelo teste de Scott \& Knott ao nível de 5\% de probabilidade.

*Isolado obtido de raízes de TOM: tomateiro; MIL: milho; CRO: crotalária; TRI: trigo. TSB: Meio líquido "trypic soy broth"

**Tempo de exposição 
Filtrados de culturas bacterianas endofíticas na motilidade, mortalidade...

TABELA 2 - Porcentagens médias de juvenis do segundo estádio $\left(\mathrm{J}_{2}\right)$ de Meloidogyne javanica imóveis, mortos e eclodidos quando expostos aos filtrados das culturas dos isolados bacterianos endofíticos (segundo ensaio in vitro)

\begin{tabular}{|c|c|c|c|c|c|}
\hline \multirow{2}{*}{ Isolado* } & \multicolumn{2}{|c|}{$\%$ de $J_{2}$ imóveis } & \multicolumn{2}{|c|}{$\%$ de $J_{2}$ mortos } & \multirow{2}{*}{$\begin{array}{r}\% \text { de } \mathrm{J}_{2} \\
\text { eclodidos }\end{array}$} \\
\hline & $24 \mathbf{h}^{* *}$ & $48 \mathrm{~h}$ & $24 \mathrm{~h}^{* *}$ & $48 \mathrm{~h}$ & \\
\hline BRA 2 & $32,25 \mathrm{e}$ & $56,75 \mathrm{c}$ & $32,25 \mathrm{~b}$ & $56,75 \mathrm{c}$ & $90,40 \mathrm{c}$ \\
\hline BRA 4 & $11,75 \mathrm{f}$ & $29,75 \mathrm{~d}$ & $11,75 \mathrm{c}$ & $29,75 \mathrm{~d}$ & $91,80 \mathrm{c}$ \\
\hline BRA 5 & $85,25 \mathrm{c}$ & $98,25 \mathrm{a}$ & $85,25 \mathrm{a}$ & $98,25 \mathrm{a}$ & $9,00 \mathrm{a}$ \\
\hline BRA 6 & $5,25 \mathrm{~g}$ & $24,00 \mathrm{e}$ & $4,25 \mathrm{c}$ & $24,00 \mathrm{e}$ & $87,20 \mathrm{c}$ \\
\hline BRA 8 & $2,75 \mathrm{~g}$ & $13,50 \mathrm{e}$ & $2,75 \mathrm{c}$ & $13,50 \mathrm{e}$ & $85,80 \mathrm{c}$ \\
\hline BRA 9 & $2,25 \mathrm{~g}$ & $27,00 \mathrm{~d}$ & $2,25 \mathrm{c}$ & $27,00 \mathrm{~d}$ & $89,20 \mathrm{c}$ \\
\hline BRA 10 & $3,00 \mathrm{~g}$ & $16,75 \mathrm{e}$ & $3,00 \mathrm{c}$ & $16,75 \mathrm{e}$ & $91,80 \mathrm{c}$ \\
\hline BRA 11 & $2,50 \mathrm{~g}$ & $58,50 \mathrm{c}$ & $2,75 \mathrm{c}$ & $58,50 \mathrm{c}$ & $76,80 \mathrm{c}$ \\
\hline BRA 12 & $4,00 \mathrm{~g}$ & $18,25 \mathrm{e}$ & $4,00 \mathrm{c}$ & $18,25 \mathrm{e}$ & $89,40 \mathrm{c}$ \\
\hline BRA 13 & $13,75 \mathrm{f}$ & $64,25 \mathrm{c}$ & $12,00 \mathrm{c}$ & $56,75 \mathrm{c}$ & $90,40 \mathrm{c}$ \\
\hline BRA 14 & $2,25 \mathrm{~g}$ & $37,75 \mathrm{~d}$ & $2,25 \mathrm{c}$ & $37,75 \mathrm{~d}$ & $90,80 \mathrm{c}$ \\
\hline BRA 15 & $94,50 \mathrm{~b}$ & 98,25 a & $94,50 \mathrm{a}$ & $98,75 \mathrm{a}$ & $20,00 \mathrm{~b}$ \\
\hline BRA 17 & $12,00 \mathrm{f}$ & $64,75 \mathrm{c}$ & $12,00 \mathrm{c}$ & $64,75 \mathrm{c}$ & $89,00 \mathrm{c}$ \\
\hline BRA 18 & $34,50 \mathrm{e}$ & $60,50 \mathrm{c}$ & $34,50 \mathrm{~b}$ & $60,50 \mathrm{c}$ & $91,40 \mathrm{c}$ \\
\hline BRA 19 & $55,00 \mathrm{~d}$ & $93,50 \mathrm{~b}$ & $55,00 \mathrm{~b}$ & $93,50 \mathrm{~b}$ & $89,60 \mathrm{c}$ \\
\hline BRA 20 & $67,25 \mathrm{~d}$ & $98,75 \mathrm{a}$ & $67,25 \mathrm{~b}$ & $98,75 \mathrm{a}$ & $88,00 \mathrm{c}$ \\
\hline MIL 7 & $64,25 \mathrm{~d}$ & $99,25 \mathrm{a}$ & $64,25 \mathrm{~b}$ & $99,25 \mathrm{a}$ & $12,00 \mathrm{a}$ \\
\hline MIL 8 & $43,25 \mathrm{e}$ & $60,00 \mathrm{c}$ & $43,25 \mathrm{~b}$ & $60,00 \mathrm{c}$ & $28,40 \mathrm{~b}$ \\
\hline MIL 13 & $41,25 \mathrm{e}$ & $66,75 \mathrm{c}$ & $41,25 \mathrm{~b}$ & $66,75 \mathrm{c}$ & $92,80 \mathrm{c}$ \\
\hline MIL 15 & $13,25 \mathrm{~d}$ & $39,50 \mathrm{~d}$ & $10,75 \mathrm{c}$ & $39,50 \mathrm{~d}$ & $84,40 \mathrm{c}$ \\
\hline ÁGUA & $0,00 \mathrm{~h}$ & $0,25 \mathrm{f}$ & $0,00 \mathrm{c}$ & $0,25 \mathrm{f}$ & $95,00 \mathrm{c}$ \\
\hline TSB & $0,50 \mathrm{~h}$ & $2,25 \mathrm{f}$ & $0,00 \mathrm{c}$ & $2,25 \mathrm{f}$ & $94,20 \mathrm{c}$ \\
\hline $\begin{array}{c}\text { ALDICARBE } \\
(50 \mathrm{ppm})\end{array}$ & $99,25 \mathrm{a}$ & $100,00 \mathrm{a}$ & $99,25 \mathrm{a}$ & $100,00 \mathrm{a}$ & $3,20 \mathrm{a}$ \\
\hline
\end{tabular}

Médias seguidas por letras distintas nas colunas, diferem entre si pelo teste de Scott \& Knott ao nível de 5\% de probabilidade.

*Isolado obtido de raízes de MIL: milho; BRA: braquiária. TSB: Meio líquido "trypic soy broth"

**Tempo de exposição

Dos dez filtrados que causaram mais de $90 \%$ de mortalidade e imobilidade $\mathrm{em} \mathrm{J}_{2}$, apenas sete não reduziram eclosão ao nível da provocada pelo aldicarbe (Tabelas 1 e 2), demonstrando que a redução na eclosão deve ser provocada, neste caso, pelas mesmas substâncias que causaram a mortalidade e imobilidade. Oka et al. (1993) verificaram que filtrados de cultura de B. cereus crescida em meio TSB, mostraram atividade nematicida a ovos de M. javanica. Contudo, nos filtrados dos isolados BRA 19 e BRA 20, não houve redução na eclosão quando comparada com a testemunha (Tabela 2), demonstrando que nesses filtrados as substâncias que afetaram a motilidade e causaram a morte de $\mathrm{J}_{2}$ não foram as mesmas capazes de reduzir a eclosão.

Embora todos os isolados testados tenham apresentado comportamentos médios semelhantes $(\mathrm{P} \leq 0,05)$, as diluições dos filtrados de culturas bacterianas endofíticas provocaram reduções sucessivas e significantes na imobilidade e mortalidade (Figura 1), bem como aumentos significantes na eclosão de $\mathrm{J}_{2}$ de $M$. javanica (Figura 2), demonstrando existência de substância tóxica no filtrado que, diluída, perde gradualmente atividade. Em média, a primeira diluição diminuiu em 10,26\% imobilidade e mortalidade e aumentou em 2,3 vezes eclosão. Na segunda diluição (1:2 v/v) a redução média da imobilização e da mortalidade foi de $35,52 \%$ e o aumento de eclosão três vezes. Já na terceira diluição $(1: 3 \mathrm{v} / \mathrm{v})$ a redução na imobilização e mortalidade foi muito maior que aqueles valores das diluições 1:1 e 1:2 (Figura 1), indicando a capacidade do $\mathrm{J}_{2}$ em se desintoxicar quando a concentração do princípio tóxico absorvido é baixa, alterando, talvez, a natureza da molécula nos centros oxidativos do pseudoceloma.
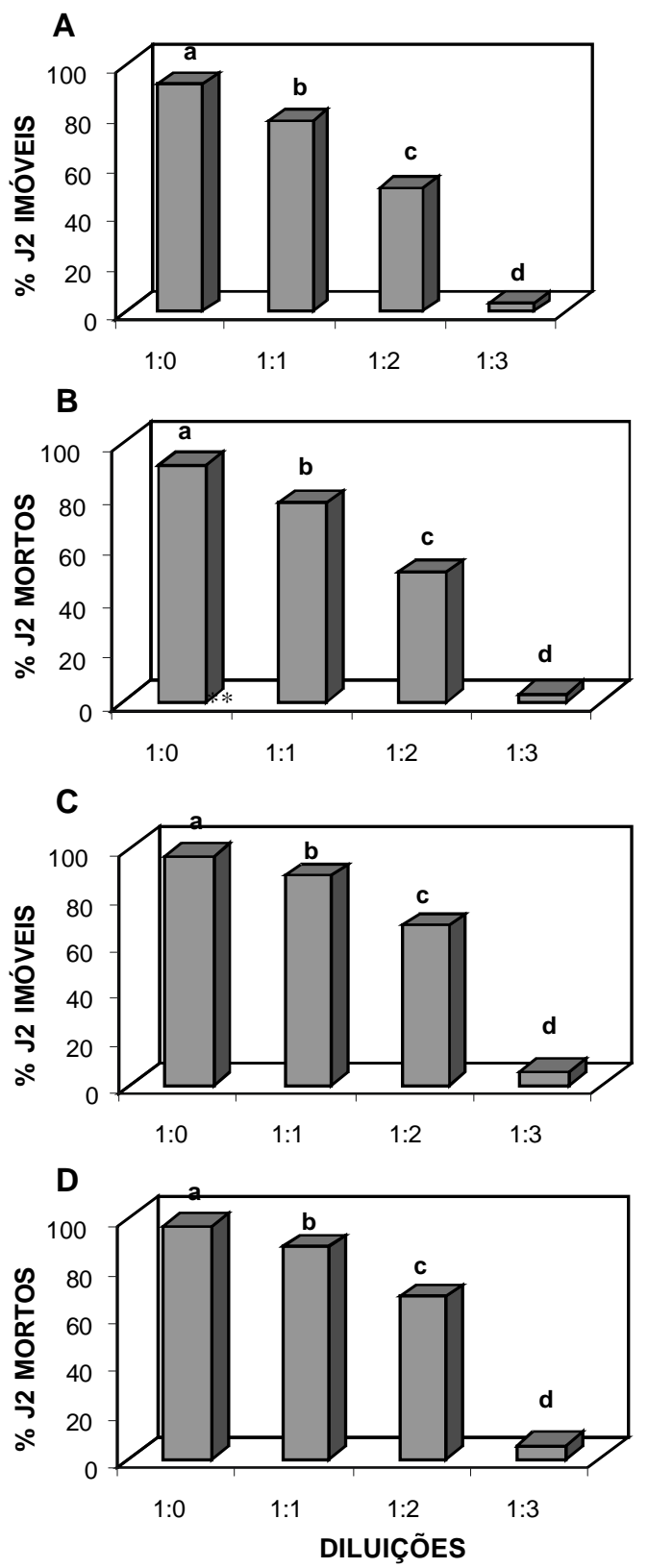

FIG. 1 - Porcentagens médias de juvenis de segundo estádio $\left(\mathrm{J}_{2}\right)$ de Meloidogyne javanica imóveis e mortos após 24 e 48 h de exposição às diferentes diluições dos filtrados de culturas de oito isolados de bactérias endofíticas. A) $\mathrm{J}_{2}$ imóveis após 24 horas; B) $\mathrm{J}_{2}$ mortos após 24 h; C) $\mathrm{J}_{2}$ imóveis após 48 h; D) $\mathrm{J}_{2}$ mortos após 48 h. Letras distintas diferem entre si pelo teste de Tukey a $5 \%$ de probabilidade. 
R.L. Naves et al.

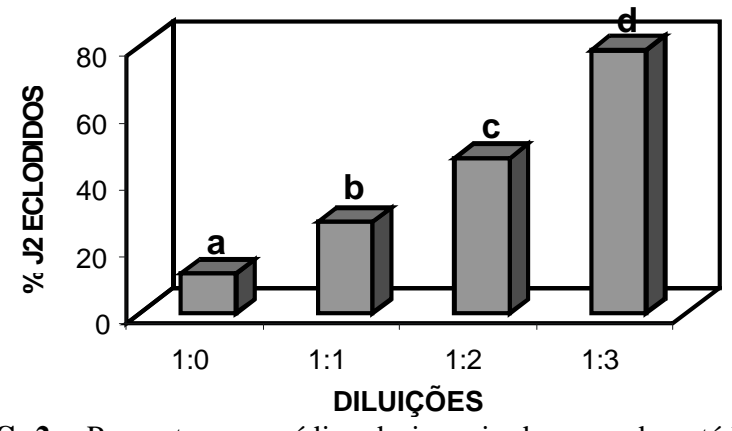

FIG. 2 - Porcentagens médias de juvenis de segundo estádio de Meloidogyne javanica eclodidos após 15 dias de exposição às diferentes diluições de filtrados de culturas de bactérias endofíticas. Letras distintas diferem entre si pelo teste de Tukey a $5 \%$ de probabilidade.

Essa hipótese, contudo, ainda necessita comprovação (Lee \& Atkinson, 1977). Resultados semelhantes foram obtidos em trabalhos com nematicidas em baixas concentrações (Huang et al., 1983; Gordon et al., 1996).

Embora tenha ocorrido aumento na diluição 1:3, as porcentagens de eclosão não aproximaram aos $95 \%$ esperados, havendo, assim, efeito inibitório significativo dos filtrados mesmo em baixas concentrações (Figura 2). Dessa forma, o referido processo de desintoxicação não foi tão eficaz no embrião quanto no $\mathrm{J}_{2}$.

Não houve interação entre os fatores isolados bacterianos e diluições, sendo que todos os isolados estudados comportaram-se de forma semelhante na redução da imobilidade e mortalidade e no aumento da eclosão, demonstrando, provavelmente, que esses isolados produzem quantidades semelhantes das substâncias tóxicas a $\mathbf{J}_{2}$ no meio líquido.

A colonização interna das raízes pelos isolados MIL 1, MIL 4, MIL 5, MIL 7, MIL 16, MIL 21, BRA 5 e BRA 15 pode, talvez, levar à proteção das mesmas contra o ataque de $M$. javanica pelo efeito tóxico direto no patógeno. Outros isolados, entretanto, podem ter outros modos de ação, induzindo mecanismos de resistência do hospedeiro a esses nematóides, o que ainda precisa ser investigado.

\section{REFERÊNCIAS BIBLIOGRÁFICAS}

ASSIS, S.M.P., SILVEIRA, E.B., MARIANO, R.L.R. \& MENEZES, D. Bactérias endofíticas - método de isolamento e potencial antagônico no controle da podridão negra em repolho. Summa Phytopathologica 24:216-220. 1998.

CAMPOS, V.P., SOUZA, J.T. \& SOUZA, R.M. Controle de fitonematóides por meio de bactérias. Revisão Anual de Patologia de Plantas 6:285-327. 1998.

CARNEIRO, R.M.D.G., SOUZA, I.S. \& BELARMINO, L.C. Nematicidal activity of Bacillus spp. strains on juveniles of Meloidogyne javanica. Nematologia Brasileira 22: 12-21. 1998.

GORDON, R., CHIPPET, J. \& TILLEY, J. Effects of two carbamates on infective juveniles of Steinernema carpocapsae all strain and
Steinernema feltiae Umeå strain. Journal of Nematology 28:310-317. 1996.

HUANG, S.P., RESENDE, I.C., SOUZA, P.E. \& CAMPOS, V.P. Effect of aldicarb, ethoprop, and carbofuran on control of coffee root-knot nematode, Meloidogyne exigua. Journal of Nematology 15:510-514. 1983.

HUSSEY, R.S. \& BARKER, K.R. A comparison of methods for collecting inocula of Meloidogyne spp. including a new technique. Plant Disease Reporter 57:1025-1028. 1973.

IGNOFFO, C.M. \& DROPKIN, V.H. Deleterious effect of the termostable toxin of Bacillus thuringiensis on species of soil inhabiting, myceliophagous, and plant parasitic nematodes. Journal of Kansas Entomological Society 50:394-398. 1977.

IIZUKA, H., KOMAGATA, T., KUNII, Y. \& SHIBUYA, M. Nematocidal action of microrganisms. Agricultural and Biological Chemistry 26:199. 1962. (Abstract)

JACQ, V.A. \& FORTUNER, R. Biological control of rice nematodes using sulphate reducing bacteria. Revue de Nematologiè 2:41-50. 1979.

JOHNSTON, T.M. Effect of fatty acids mixtures on the rice stylet nematode (Tylenchorhynchus martini Fielding, 1956). Nature 183:1392. 1959.

LEE, D.L. \& ATKINSON, H.J. Physiology of nematodes. 2nd ed. New York: Columbia University Press, 1977.

MARIANO, R.L.R., ASSIS, S.M.P., MELLO, M.R.F., MOURA, F.F., ANDRADE, A.Q.V. \& SILVA,G. Método de isolamento de bactérias endofíticas. Fitopatologia Brasileira 22:235. 1997. (Resumo)

McINROY, J.A. \& KLOEPPER, J.W. Survey of indigenous endophytes from cotton and sweet corn. Plant and Soil 173:337-342. 1995.

MISAGHI, I. J. \& DONNDELINGER, C. R. Endophytic bacteria in symptom-free cotton plants. Phytopathology 80:808-811. 1990.

OKA, Y., CHET, I. \& SPIEGEL, Y. Control of the root-knot nematode Meloidogyne javanica by Bacillus cereus. Biocontrol Science and Technology 3:115-126. 1993.

QUADT-HALLMANN, A., HALLMANN, J., RODRÍGUEZKÁBANA, R. \& KLOEPPER, J.W. Nematode interactions with endophytes II: effect of nematode density on colonization of endophytic bacteria. Anais, III International Nematology Congress, Gosier, Guadeloupe Antilles, French West Indies, 1996. pp.135-136.

RODRÍGUEZ-KÁBANA, R., JORDAN, J.W. \& HOLLIS, J.P. Nematodes biological control in rice fields: role of hydrogen sulfide. Science 148:524. 1965.

SAYRE, R.M. Biocontrol: Bacillus penetrans and related parasites of nematodes. Journal of Nematology 12:260-270. 1980.

SCOTT, A.J. \& KNOTT, M. A cluster analysis method for grouping means in the analysis of variance. Biometrics 30: 507-512. 1974.

SIKORA, A. \& HOFFMANN-HERGARTEN, S. Nematode interactions with plant health promoting rhizobacteria. Anais, III International Nematology Congress, Gosier, Guadeloupe Antilles, French West Indies. 1996. pp.72-73.

TAYLOR, A.L. \& SASSER, J.N. Biology, identification and control of root-knot nematodes (Meloidogyne species). North Carolina: International Meloidogyne Project. 1978.

WILT, G.R. \& SMITH, R.E. Studies on the interactions of aquatic bacteria and aquatic nematodes. Water Resources Research Institute Bulletin 1:701. 1970.(Abstract) 